\title{
A LAGRANGIAN DUAL METHOD FOR SOLVING VARIATIONAL INEQUALITIES
}

\author{
STEFAN M. STEFANOV
}

Abstract. In this paper we consider a variational inequality problem (VIP) defined by a maximal monotone operator and a feasible set defined by convex inequality constraints and bounds on the variables. A Lagrangian dual method for solving this problem is presented and its convergence is proved.

Mathematics subject classification (2000): 49J40, 49N15, 65K10, 90C33.

Key words and phrases: variational inequalities, complementarity problems, dual methods.

\section{REFERENCES}

[1] R. ANDREANI AND J. M. MARTÍNEZ, "Reformulation of variational inequalities on a simplex and compactification of complementarity problems”, SIAM Journal on Optimization, 10 (2000) No. 3, 878-895.

[2] A. Auslender, R. COMINETTI, AND M. HADDOU, “Asymptotic analysis of penalty and barrier methods in convex and linear programming”, Mathematics of Operations Research, 22 (1997) 43-62.

[3] A. Auslender, M. Teboulle, And S. Ben-TiBA, "A logarithmic-quadratic proximal method for variational inequalities”, Computational Optimization and Applications, 12 (1998) 31-40.

[4] A. Auslender, M. Teboulle, And S. Ben-TiBA, "Interior proximal and multiplier methods based on second order homogeneous kernels”, Mathematics of Operations Research, 24 (1999) 645-668.

[5] J.-P. CROUZEIX, P. MARCotTE, AND D. ZHU, "Conditions ensuring the applicability of cutting-plane methods for solving variational inequalities”, Mathematical Programming, 88 (2000) No. 3, 521-539.

[6] A. L. DONTCHEV AND R. T. ROCKAFELlAR, "Characterizations of strong regularity for variational inequalities over polyhedral sets”, SIAM Journal on Optimization, 6 (1996) 1087-1105.

[7] F. FACCHINEI AND C. KANZOW, "Beyond monotonicity in regularization methods for nonlinear complementarity problems”, SIAM Journal on Control and Optimization, 37 (1999) 1150-1161.

[8] M. FuKUSHIMA, "Equivalent differentiable optimization problems and descent methods for asymmetric variational inequality problems”, Mathematical Programming, 53 (1992) 99-110.

[9] S. A. Gabriel, J. J. MorÉ, “Smoothing of mixed complementarity problems”, In: Complementarity and Variational Problems: State of the Art, M. C. Ferris and J. S. Pang, eds., SIAM, Philadelphia, 1997, pp. 105-116.

[10] J.-L. GofFin, P. MARCOTTE, AND D. L. ZHU, “An analytic center cutting plane method for pseudomonotone variational inequalities”, Operations Research Letters, 20 (1997) 1-6.

[11] D. KInderlehrer, G. STAMPACCHIA, An Introduction to Variational Inequalities and Their Applications, Academic Press, New York, 1980.

[12] HANS-JACOB LÜTHI AND BENNO BÜELER, "The analytic center quadratic cut method for strongly monotone variational inequality problems", SIAM Journal on Optimization, 10 (2000) No. 2, 415-426.

[13] O. L. MANGASARIAN AND M. V. Solodov, "Nonlinear complementarity as unconstrained and constrained minimization”, Mathematical Programming, 62 (1993) 277-297.

[14] P. Marcotte AND J. P. Dussault, "A note on a globally convergent Newton method for solving monotone variational inequalities”, Operations Research Letters, 6 (1987) 35-42.

[15] Y. NESTEROV AND J.-P. VIAL, "Homogeneous analytic center cutting plane methods for convex problems and variational inequalities”, SIAM Journal on Optimization, 9 (1999) 707-728. 
[16] J. M. PENG, "Equivalence of variational inequality problems to unconstrained optimization", Mathematical Programming, 78 (1997) 347-355.

[17] H.-D. QI, “A regularized smoothing Newton method for box constrained variational inequality problems with $P_{0}$ - functions", SIAM Journal on Optimizationz, 10 (2000), No. 2, 315-330.

[18] L. QI, J. SUN, “A nonsmooth version of Newton's method”, Mathematical Programming, 58 (1993) 691-714.

[19] R. T. Rockafellar AND R. J.-B. WeTs, Variational Analysis, Springer-Verlag, Berlin Heidelberg New York, 1998.

[20] M. SOLODOV AND B. SVAITER, "A hybrid projection-proximal point algorithm", Journal on Convex Analysis, 6 (1999) 59-70.

[21] M. V. SOLODOV AND B. F. SVAITER, "A trully globally convergent Newton-type method for the monotone nonlinear complementarity problem", SIAM Journal on Optimization, 10 (2000) No. 2, 605-625.

[22] G. SONNEVEND, "An "analytic center" for polyhedrons and new classes of global algorithms for linear (smooth, convex) programming", in: Proceedings of the 12th IFIP Conference, Budapest 1985, A. Prekopa, J. Szelezsan, and B. Strazicky, eds., Lecture Notes in Control and Information Sciences 84, Springer, Berlin, 1985, pp. 866-876.

[23] S. M. STEFAnov, "Convex separable minimization subject to bounded variables", Computational Optimization and Applications. An International Journal, 18 (2001) No. 1, 27-48.

[24] S. M. StEFAnOv, Separable Programming. Theory and Methods, Applied Optimization, vol. 53, Kluwer Academic Publishers, Boston Dordrecht London, 2001.

[25] K. TAJI, M. FUKUSHIMA, AND T. IBARAKI, "A globally convergent Newton method for solving strongly monotone variational inequalities”, Mathematical Programming, 58 (1993) 369-383.

[26] N. YAMASHITA, K. TAJI, AND M. FUKUSHIMA, "Unconstrained optimization reformulations of variational inequality problems", Journal of Optimization Theory and Applications, 92 (1997) 439-456. 